\title{
CONTROLE DE PATÓGENOS EM SEMENTES DE SORGO COM ÓLEO ESSENCIAL DE Cymbopogon citratus (D. C.) Stapf
}

\author{
SENEME, Adriana Martinelli ${ }^{1}$ \\ SILVA, Fernanda Chemim ${ }^{2}$ \\ RUARO, Lucimeris $^{3}$ \\ FERRIANI, Aurea Portes ${ }^{4}$ \\ MORAES, Carla Pedroso de
}

\begin{abstract}
RESUMO: O presente trabalho teve por objetivo avaliar a eficiência do óleo essencial de Cymbopogon citratus na qualidade sanitária e fisiológica de sementes de sorgo do cultivar XB6020. O experimento utilizou sementes de sorgo tratadas com óleo essencial de $C$. citratus nas concentrações de $0,0,25 \%, 0,50 \%, 1 \%$ e 1,5\%. Foram avaliadas as seguintes características: sanidade de sementes pelo método de Blotter test, primeira contagem de germinação, germinação e peso de massa seca das plântulas normais. A análise foi feita utilizando delineamento inteiramente ao acaso (DIC) com cinco concentrações e cinco repetições, em dois ensaios separados, para verificação da sanidade e avaliação da qualidade fisiológica das sementes. Concluiu-se que o óleo essencial de capim-limão (C. citratus) reduz a infestação de fungos, principalmente de Fusarium spp., porém, pode induzir o desenvolvimento de Penicillium spp. e em concentração de 1,5\% apresenta efeito fitotóxico reduzindo a germinação e o vigor das sementes de sorgo.
\end{abstract}

Palavras-Chave: Sorghum bicolor. Fungitoxidade. Sanidade de sementes. Germinação. Alelopatia.

SUMMARY: This study aimed evaluate the efficiency of Cymbopogon citratus essential oil in the sanitary and physiological quality of sorghum seeds of cultivar XB6020. The experiment used sorghum seeds treated with essential oil of $\mathrm{C}$. citratus at concentrations of $0,0,25 \%, 0,50 \%, 1 \%$ and $1,5 \%$. The following characteristics were evaluated: seed health by Blotter test method, first germination count, germination and dry mass weight of normal seedlings. The analysis was done using a completely randomized design (DIC) with five concentrations and five replicates, in two separate tests, one to check the sanity and evaluation of physiological quality of the seeds. The essential oil of lemon grass (C. citratus) reduces the infestation of fungi, mainly of Fusarium, however, it may induce the development of Penicillium; and at $1.5 \%$ concentration presents a phytotoxic effect reducing the germination and vigor of sorghum seeds.

Keywords: Sorghum bicolor. Fungitoxicity. Seed health. Germination. Allelopathy.

\section{INTRODUÇÃO}

As sementes podem ser um meio de disseminação de patógenos quando infectadas por microrganismos patogênicos (PESKE et al., 2006). Sua qualidade sanitária está diretamente relacionada com a produtividade da cultura, sendo grande a quantidade de patógenos que podem estar associados a elas e podem comprometer o bom desempenho das plantas. Quando associados às sementes, os microrganismos patogênicos, podem comprometer a germinação e causar uma série de danos, entre eles, o baixo vigor devido a deterioração de tecidos embrionários, mortes na pré-emergência da plântula,

\footnotetext{
${ }^{1}$ Profa Adjunto IV, Dra, Departamento Fitotecnia E Fitossanidade- Universidade Federal Do Paraná

${ }^{2}$ Eng. Agrônoma, Universidade Federal do Paraná

${ }^{3}$ Profa, Dra, Departamento Fitotecnia e Fitossanidade- Universidade Federal Do Paraná

${ }^{4}$ Bióloga, Dra, Universidade Federal do Paraná

${ }^{5}$ Profa Dra Adjunto - UTP - UTP - Universidade Tuiuti do Paraná
} 
tombamentos, podridões radiculares, manchas necróticas em folhas, caules, frutos e sistema vascular, deformações, descolorações, infecções latentes (MACHADO, 1988; MOREAU, 2011; PIVETA et al., 2010).

O tratamento químico de sementes vem sendo um importante procedimento na produção agrícola (MACHADO, 2000; VILLELA, 2015). No entanto, para o cultivo em agricultura orgânica, não é possível o uso de fungicidas químicos sendo necessária a busca por alternativas para o tratamento das sementes que serão utilizadas

O emprego de substâncias naturais com ação fungicida surge como uma opção de baixo impacto ecológico e ambiental, menor risco de contaminação de alimentos, redução de custos, podendo ser utilizados na proteção natural de plantas e indicado no controle de doenças provocadas por fungos e bactérias (GOMES et al., 2008; XAVIER et al., 2012). A utilização de extratos (óleos fixos) e óleos essenciais (voláteis) de plantas medicinais, condimentares e aromáticas com potencial para o manejo de doenças de plantas apresenta-se atualmente como alternativa ao uso de produtos tóxicos. Isso possibilita sistemas de cultivo menos dependentes ao uso de agroquímicos e são mais sustentáveis (SEIXAS et al., 2011). Diferentes estudos mostram o efeito de óleos essenciais de plantas como fungicidas naturais inibindo a atividades fúngicas em frutos e plantas (ABREU, 2006; MEDICE et al., 2007; ROZWALKA, 2008, SOUSA et al., 2012).

O óleo essencial de capim-limão é rico em citral e limoneno e a ação fungitóxica desses compostos foi confirmada em estudo de GUIMARÃES et al. (2011) em micélios de Fusarium oxysporum cubense, Colletotricum gloesporioides, Bipolaris spp. e Alternaria alternata e também em trabalho de Combrinck et al. (2011) em Lasiodiplodia theobromae, Colletotrichum gloeosporioides, Alternaria citrii, Botrytis cinerea e Penicillium digitatum isolados de manga, abacate, cítricos, uva e pêra de cacto. Pesquisas têm atribuído à espécie outras atividades biológicas, tais como ação inseticida (ALBO et al., 2016; LIMA et al., 2008), antimicrobiana (SANTOS et al., 2009) e antibacteriano (PEREIRA et al., 2004).

Buscando ampliar a base de informações sobre o efeito de óleos essenciais na germinação de sementes e no desenvolvimento de plântulas, como uma forma alternativa de tratamento de sementes, o trabalho teve como objetivos identificar os efeitos da aplicação de soluções com diferentes concentrações do óleo essencial de capim limão (Cymbopogon citratus) na qualidade fisiológica e sanitária de sementes de sorgo.

\section{MATERIAL E MÉTODO}

\section{Extração do óleo essencial}

Foram coletadas folhas da planta de capim limão (Cymbopogon citratus, Poaceae) no início do outono (18 de abril de 2017), no período da manhã, na Fazenda Experimental Canguiri, em Pinhais (PR) no Setor de Plantas Medicinais. Após a coleta, a massa fresca foi cortada em pedaços de aproximadamente $1 \mathrm{~cm}$ e inseridas nos balões de fundo redondo, com 2 litros de capacidade, do aparelho graduado tipo Clevenger, no Laboratório de Ecofisiologia, Departamento de Fitotecnia e Fitossanidade (UFPR, Curitiba, PR). Em cada balão foram colocados 2/3 do volume de massa do material e 1litro de água destilada. A extração do óleo deu-se por hidrodestilação, com utilização do sistema Clevenger, em modo de arraste de vapor com fervura durante 2,5 horas.

$\mathrm{O}$ hidrolato foi coletado com micropipeta e armazenado em frascos Ependorf de $2 \mathrm{ml}$, a $-20^{\circ} \mathrm{C}$, até a realização da análise de seus componentes químicos. Para a análise de composição, o óleo foi centrifugado por 20 segundos para_separação de resíduos de água presente no óleo. Posteriormente o óleo foi Nucleus,v.16,n.2,out.2019 
coletado com micropipeta e armazenado em frasco de vidro âmbar, $(10 \mathrm{~mL})$ em freezer, a baixa temperatura $\left(-20^{\circ} \mathrm{C}\right)$ e ao abrigo de luminosidade.

\section{Análise cromatográfica do óleo essencial}

A análise qualitativa do óleo essencial de $C$. citratus foi realizada por cromatografia em fase gasosa acoplada a espectrometria de massas (CG/EM), em cromatógrafo Agilent 6890 acoplado a detector seletivo de massas Agilent 5973N, com detector de ionização de chamas (FID). A descrição dos componentes do óleo está na Tabela 1.

\section{Tratamento e qualidade fisiológica das sementes de sorgo}

O óleo essencial de $C$. cirtatus foi solubilizado com Tween $80(1 \%)$ e dissolvido em água destilada para a obtenção de soluções nas concentrações de $0,25 \%, 0,50 \%, 1,0 \%$ e 1,5\%. Como controle utilizou-se uma solução de Tween 80 (1\%) sem adição de óleo.

As sementes de sorgo foram imersas nas soluções durante cinco minutos, e em seguida, foram retiradas (com auxílio de uma peneira) e colocadas sobre duas folhas de papel toalha para retirar o excesso de solução. Na sequência, as sementes foram dispostas sobre duas folhas de papel filtro umedecidos com água, dentro de caixas plásticas transparentes com tampas ("gerbox"), previamente desinfestadas com solução de hipoclorito de sódio (1\%). As caixas "gerbox" foram acondicionadas em câmara BOD na temperatura de $25^{\circ} \mathrm{C}$ durante 10 dias. As avaliações da germinação ocorreram no $4^{\circ}$ e $10^{\circ}$ dia após a instalação do teste e o teste de primeira contagem da germinação foi usado como avaliação do vigor (PCG) (BRASIL, 2009a; NAKAGAWA, 1994). Ao final do teste de germinação, as plântulas foram secas em estufa a $60^{\circ} \mathrm{C}$ durante 72 horas e determinou-se o peso de matéria seca por plântula em balança com duas casas decimais. O peso total foi dividido pelo número de plantas normais e obteve-se o peso de matéria seca por plântula (PMS/PL) (NAKAGAWA, 1994).

\section{Qualidade sanitária das sementes ("Blotter test")}

Com as sementes tratadas realizou-se também o Teste de Sanidade pelo método do papel de filtro ("Blotter test") com congelamento. Foram realizadas cinco repetições com 30 sementes em cada "gerbox" (caixas plásticas transparentes com tampa) e a avaliação ocorreu no $10^{\circ}$ dia após a instalação (BRASIL, 2009b).

Os dados foram analisados em delineamento inteiramente casualizado com cinco repetições para os testes de germinação e sanidade (total de 150 sementes para cada teste); realizou-se análise de variância e após, as médias dos tratamentos foram comparadas pelo teste de Tukey (5\%).

\section{RESULTADO E DISCUSSÃO}

As sementes de sorgo XB6020 apresentaram peso médio de 100 sementes de 3,77g, $95 \%$ de germinação e 12,2\% de teor de água. Os principais componentes do óleo essencial de capim limão foram o geranial $(41,97 \%)$ e o neral $(31,93 \%)$ (Tabela 1$)$. 
Tabela 1. Principais componentes do óleo essencial de Cymbopogon citratus.

\begin{tabular}{llll}
\hline Componente & IR a & IR b & $\%$ \\
\hline B-mirceno & 990 & 988 & 16,52 \\
Neral & 1242 & 1235 & 31,93 \\
Geraniol & 1254 & 1249 & 2,32 \\
Geranial & 1273 & 1264 & 41,97 \\
$\mathrm{Ni}^{1}$ & - & - & 7,27 \\
\hline Total & & & 100 \\
\hline
\end{tabular}

${ }^{1}$ Não identificado

Fonte: Adaptado por KOGERATSKI J. F. (2017).

IRa - Índice de Retenção encontrado na literatura;

$\mathrm{IRb}$ - Índice de Retenção encontrado no trabalho.

Os componentes majoritários do óleo pertencem à classe dos monoterpenos característicos do gênero (CASTRO et al, 2010), descritos como promotores de diversas atividades biológicas, dentre as quais a antinfúngica conforme citado por Santos et al. (2009).

A Tabela 2 refere-se ao efeito do óleo essencial na qualidade fisiológica das sementes. Houve diferença significativa entre as concentrações do óleo essencial para primeira contagem da germinação, germinação e sementes não germinadas, mas não houve efeito no peso de matéria seca plântula. Na concentração 1,5\% ocorreu redução significativa tanto do vigor (avaliado pela PCG) como da germinação (GE), e aumento significativo de sementes não germinadas (Tabela 2) quando comparados a testemunha.

Tabela 2. Efeito do óleo essencial, em diferentes concentrações, de Cymbopogon citratus sobre a qualidade fisiológica das sementes de sorgo: primeira contagem de germinação (PCG), germinação (GE), peso de massa seca por plântula (PMS/PL) e sementes não germinadas.

\begin{tabular}{ccccc}
\hline Concentração & PCG & GE & PMS/PL & $\begin{array}{c}\text { Sementes não } \\
\text { germinadas } \\
(\%)\end{array}$ \\
\hline 0,00 & $95 \mathrm{a}^{1}$ & $93 \mathrm{a}$ & $0,01842 \mathrm{a}$ & $(\%)$ \\
0,25 & $97 \mathrm{a}$ & $96 \mathrm{a}$ & $0,01938 \mathrm{a}$ & $3 \mathrm{~b}$ \\
0,50 & $91 \mathrm{ab}$ & $92 \mathrm{a}$ & $0,02084 \mathrm{a}$ & $3 \mathrm{~b}$ \\
1,00 & $82 \mathrm{~b}$ & $81 \mathrm{a}$ & $0,01863 \mathrm{a}$ & $6 \mathrm{~b}$ \\
1,50 & $35 \mathrm{c}$ & $62 \mathrm{~b}$ & $0,02024 \mathrm{a}$ & $17 \mathrm{~b}$ \\
\hline $\mathrm{CV}(\%)$ & 8,03 & 10,5 & 8,85 & 62,57 \\
\hline
\end{tabular}

${ }^{1}$ As médias seguidas pela mesma letra, na coluna, não diferem estatisticamente entre si pelo teste de Tukey (5\%).

No teste de sanidade observou-se nas sementes de sorgo a presença de fungos dos gêneros, Penicillium (14\%), Fusarium (11\%), Aspergillus (1\%), Curvularia (1\%) e Hexserohilum (1\%). Porém, a quantidade presente dos gêneros Aspergillus, Curvularia e Hexserohilum, não foi considerada significativa o suficiente para aplicação de análise estatística. Assim, a análise foi feita apenas para os gêneros Penicillium e Fusarium.

Flávio et. al. (2014) também encontraram nas sementes de sorgo, os fungos dos gêneros, Penicillium (12,8\%), Curvularia (43\%), Fusarium (29,2\%) e Aspergillus (14,3\%) como maior incidência. Da mesma forma, Netto et al. (1998), observaram como sendo os principais fungos ocorrentes em sementes de sorgo, os gêneros Penicillium, Aspergillus, Rizophus, Alternaria, Curvularia e Fusarium. 
A incidência dos fungos presentes nas sementes de sorgo após o tratamento está descrita na Tabela 3. Houve redução significativa na porcentagem de sementes contaminadas a partir da concentração de $0,25 \%$. Na concentração $0,50 \%$, ocorreu aumento da quantidade de fungos, em geral, presentes nas sementes e na concentração de 1,5\% não houve presença de fungos nas sementes (Tabela 3). Porém, nessa concentração houve redução significativa da germinação das sementes (62\%) comparado aos demais tratamentos. Leite et al. (2018) também observaram redução da germinação de sementes de feijão (de $82 \%$ para $41 \%)$ após o tratamento com C. citratus, porém utilizando o óleo puro por impregnação $(3 \mathrm{ml} / 1,3 \mathrm{~kg}$ de sementes). O mesmo efeito prejudicial na germinação de sementes de feijão foi verificado por Morais et al. (2008) com redução da germinação de $82 \%$ para $53 \%$ usando a concentração de $5 \%$.

Tabela 3. Efeito do tratamento das sementes com diferentes concentrações da solução de Cymbopogon citratus sobre a incidência de fungos nas sementes de sorgo.

\begin{tabular}{ccccc}
\hline $\begin{array}{c}\text { Concentração } \\
(\boldsymbol{\%})\end{array}$ & $\begin{array}{c}\text { Fungos em geral } \\
(\boldsymbol{\%})\end{array}$ & $\begin{array}{c}\text { Penicillium spp } \\
(\boldsymbol{\%})\end{array}$ & $\begin{array}{c}\text { Fusarium spp } \\
(\boldsymbol{\%})\end{array}$ & $\begin{array}{c}\text { Sementes limpas } \\
(\boldsymbol{\%})\end{array}$ \\
\hline 0 & $62 \mathrm{a}$ & $13 \mathrm{~b}$ & $42 \mathrm{a}$ & $38 \mathrm{c}$ \\
0,25 & $26 \mathrm{bc}$ & $14 \mathrm{ab}$ & $9 \mathrm{~b}$ & $74 \mathrm{ab}$ \\
0,50 & $43 \mathrm{ab}$ & $33 \mathrm{a}$ & $6 \mathrm{~b}$ & $57 \mathrm{bc}$ \\
1,00 & $9 \mathrm{c}$ & $9 \mathrm{~b}$ & $0 \mathrm{~b}$ & $91 \mathrm{a}$ \\
1,50 & $0 \mathrm{c}$ & $0 \mathrm{~b}$ & $0 \mathrm{~b}$ & $100 \mathrm{a}$ \\
\hline
\end{tabular}

As médias seguidas pela mesma letra, na coluna, não diferem estatisticamente entre si pelo teste de Tukey (5\%).

O aumento na porcentagem de fungos em geral na concentração de $0,50 \%$ é reflexo do aumento acentuado de Penicillium spp. nesta concentração. É possível que algum componente presente no óleo essencial de $C$. citratus tenha promovido o desenvolvimento do fungo. Nas outras concentrações o fungo Penicillium spp. não apresentou diferenças em relação ao controle. Foi possível observar que a partir da concentração $0,50 \%$ houve incidência de bactérias, que não foram identificadas, o que pode sugerir a ocorrência de competição com o fungo Penicillium spp., impedindo assim a continuação de seu desenvolvimento nas concentrações acima de 0,50\%. Não se sabe se o impedimento de incremento do Penicillium spp. nas concentrações maiores que $0,50 \%$ foi devido à presença de bactérias, ou à ação do óleo essencial. Esses resultados concordam parcialmente com Leite et al. (2018) em sementes de feijão, que observaram que o tratamento com C.citratus não foi eficiente para o controle do Penicillium spp. e que houve aumento na porcentagem de bactérias nas sementes tratadas com o óleo essencial. Resultados obtidos por Morais et. al. (2008), que analisaram diferentes óleos essenciais sobre a semente de feijão mostraram que o óleo essencial de $C$. citratus reduziu significativamente a incidência de Penicillium (de 24 para 7,8\%), porém com o uso de solução a 5\%, prejudicando a germinação.

Em relação ao Fusarium, este foi o que apresentou melhor interação com o óleo essencial de $C$. citratus, diferindo do controle e apresentando acentuada redução de sua incidência a partir da concentração 0,25\%. Bolkan e Ribeiro (1991) e Cruz et al. (1997), também encontraram em seus estudos controle eficiente do Fusarium pelo uso do óleo essencial de $C$. citratus, que inibiu o crescimento micelial e a germinação de esporos, o que corrobora com os resultados do presente trabalho.

Muitos outros autores encontraram a eficiência antifúngica do óleo essencial de capim-limão para diversos patógenos isolados. Alves et al. (2002), observaram eficiência de $C$. citratus na inibição da germinação "in vitro" de conídios de Colletotrichum musae. Silva et al. (2009) relataram o controle "in vitro" de C. citratus sobre o patógeno Colletotrichum gloeosporioides isolados de maracujazeiro. Lorenzetti et al. (2012) mostraram a eficiência do capim-limão na inibição de esporos de Puccinia nakanishikii e também Pereira et al. (2011), relataram o controle de Cercospora coffeicola com o uso do capim-limão. 
Para os gêneros dos fungos Aspergillus, Curvularia e Hexserohilum, apesar de não terem sido analisados estatisticamente, foi observado sua inibição com o aumento da concentração do óleo essencial, evidenciando o controle destes gêneros pelo uso do óleo essencial de C. citratus. A continuidade das pesquisas pode contribuir para a ampliação da base de dados para alternativas ambientalmente corretas para o controle de agentes patogênicos em armazenamento de grãos.

\section{CONCLUSÃO}

O óleo essencial de capim-limão (C. citratus) reduz a infestação de fungos, principalmente de Fusarium spp, porém, pode induzir o desenvolvimento de Penicillium spp. Na concentração 1,5\% apresenta efeito fitotóxico, reduzindo a germinação e o vigor das sementes de sorgo.

\section{REFERÊNCIAS}

ABREU, C. L. M. Controle de Alternaria solani em tomateiro (Lycopersicon esculentum) com óleos essenciais. Tese (Doutorado em Agronomia - Horticultura) - Faculdade Ciências Agronômicas, Universidade Estadual Paulista, Botucatu, 2006. 71p.

ALBO, G. N.et al. Evaluación de la actividad inhibitoria, in vivo e in vitro, del aceite esencial de Cymbopogon citratus y cinco diluyentes sobre cultivos de Ascosphaera apis. Analecta Vet., v. 36, n.1, p. 5-11, 2016.

ALVES, E.S.S.et al. Eficiência de óleos essenciais no controle in vitro da germinação de conídios e do crescimento micelial de Colletotrichum musae. Fitopatologia Brasileira, Brasília, v. 27, p.75. 2002.

BOLKAN, H.A.; RIBEIRO, W.R.C. Efeito do extrato e de óleos de alho em Cylindrocladium clavatum, Fusarium moniliforme var. subglutinans e Rhizoctonia solani. Fitopatologia Brasileira, p. 565- 566. 1991.

BRASIL. Ministério da Agricultura, Pecuária e Abastecimento. Regras para análise de sementes. Brasília: Mapa/ACS, 2009a. 399p.

BRASIL. Ministério da Agricultura, Pecuária e Abastecimento. Manual de análise sanitária de sementes. Brasília: MAPA/ACS, 2009b. 200p.

CASTRO, H. G. et al. Avaliação do teor e composição do óleo essencial de Cymbopogon nardus (L.) em diferentes épocas de colheita. Revista Ciência Agronômica, v. 41 n. 2, p. 308-314. 2010.

COMBRINCK, S.; REGNIER, T.; KAMATOU, G.P.P. In vitro activity of eighteen essential oils and some major components against common postharvest fungal pathogens of fruit. Industrial Crops and Products. v.33, p.344-349, 2011.

CRUZ, M.E.S.et al. Efeito do óleo essencial de Cymbopogon citratus (capim limão) no crescimento micelial de fungos fitopatogênicos. Summa Phytopathologica, p.63-65. 1997.

FLAVIO, N. S. D. S.et al. Qualidade sanitária e fisiológica de sementes de sorgo tratadas com extrato aquoso e óleo essencial. Ciências Agrárias, Londrina, v. 35, n. 1, p. 7-10, jan/fev. 2014.

GOMES D. P. Efeito do óleo de nim na qualidade sanitária e fisiológica de sementes de soja. XII Encontro Latino Americano de Iniciação Científica. INIC: São José dos Campos-SP, 2008. 
GUIMARÃES, L. G. de L.; CARDOSO, M. das G.; SOUSA, P. E. de; ANDRADE, J. de; VIEIRA, S. S. Atividades antioxidante e fungitóxica do óleo essencial de capim-limão e do citral. Revista Ciência Agronômica, Fortaleza, v.42, n.2, p.464-472, 2011.

KOGERATSKI, J.F. Qualidade fisiológica e sanitária de sementes de feijão tratadas com óleo essencial de Cymbopogon citratus (D. C.) Stapf. 46p. Trabalho de Conclusão de Curso (Graduação em Agronomia), Universidade Federal do Paraná, UFPR, -2017.

LEITE, K.et al. Óleos essenciais no tratamento de sementes de Phaseolus vulgaris L. durante o armazenamento. Revista Verde de Agroecologia e Desenvolvimento Sustentável, v.13, n.2, p.186-199, 2018.

LIMA, R.et al. Composição dos óleos essenciais de Anis-estrelado Illicium verum L. e de Capim-limão Cymbopogon citratus (DC.) Stapf: Avaliação do efeito repelente sobre Brevicoryne brassicae (L.)(Hemiptera: Aphididae). Bio Assay, v.3, n.8, p.1-6, 2008.

LORENZETTI, E.R.et al. Controle da ferrugem das folhas do capim-limão (Cymbopogon citratus (DC.) Stapf) com produtos naturais. Revista Brasileira de Plantas Medicinais, Botucatu, v. 14, n. 4, p. 571578. 2012.

MACHADO, J. da C. Patologia de sementes: fundamentos e aplicações. Brasília: Ministério da Educação, Lavras: ESAL/FAEPE, 1988.

MACHADO, J. da C. Tratamento de sementes no controle de doenças. Lavras, MG: UFLA, 2000.

MEDICE, R.et al. Óleos essenciais no controle de ferrugem asiática da soja Phakopsora pachyrhizi Syd. e Phakopsora Syd. Ciência e Agrotecnologia, v.31, p. 83-90. 2007.

MORAIS, L.A.S.et al. Atividade antifúngica de óloes essenciais em sementes de feijão cv. Carioquinha. Horticultura Brasileira v. 26, n.2 (Suplemento CD Rom), jul.-ago., S6261- S6266, 2008.

MOREAU, J. S. Germinação de sementes em diferentes substratos e caracterização morfológica de plântulas de Anadenanthera macrocarpa (Benth.) Brenan. 45p. Monografia (Graduação em Agronomia), Universidade Federal do Espírito Santo, Alegre, 2011.

NAKAGAWA, J. Testes de vigor baseados na avaliação de plântulas. In: VIEIRA, R.D., CARVALHO, N.M. (ed). Testes de vigor em sementes. Jaboticabal: FUNEP, 1994. p.49-85.

NETTO, D.M.et al. Qualidade fisiológica e sanitária de sementes de sorgo danificadas. Revista Brasileira de Sementes, v. 20, n. 2, p. 134-140, 1998.

PEREIRA, R. S.et al. Atividade antibacteriana de óleos essenciais em cepas isoladas de infecção urinária. Revista Saúde Pública, v.38, n.2, p.326-328, 2004.

PEREIRA, R.B.et al. Potential of essential oils for the control of brown eye spot in coffee plants. Ciência e Agrotecnologia. Lavras. v.35, n.1, p.115-123, 2011.

PESKE, S. T., LUCCA FILHO, O. A., BARROS, A. C. S. A. Produção de Sementes, in: Sementes: Fundamentos Científicos e Tecnológicos. 2 ed. Pelotas: Ed. Universitária/ UFPel, 2006, p.12-93.

PIVETA, G.et al. Superação de dormência na qualidade de sementes e mudas: influência na produção de Senna multijuga (LC Rich.) Irwin \& Barneby. Acta Amazônica, v. 40, n. 2, p.281-288, 2010.

ROZWALKA, L. C.et al. Extratos, decoctos e óleos essenciais de plantas medicinais e aromáticas na inibição de Glomerella cingulata e Colletotrichum gloeosporioides de frutos de goiaba. Ciência Rural, Santa Maria, v. 38, n. 2, p. 301-307, 2008. 
SANTOS, A.et al. Determinação do rendimento e atividade antimicrobiana do óleo essencial de Cymbopogon citratus (DC.) Stapf em função de sazonalidade e consorciamento. Revista Brasileira de Farmacognosia, v.19, n.2A, p. 436-441, 2009.

SEIXAS, P.T.Let al. Controle fitopatológico do Fusarium subglutinans pelo óleo essencial do capimcitronela (Cymbopogon nardus L.) e do composto citronelal. Revista Brasileira de Plantas Medicinais. v.13, p.513-517, 2011.

SOUSA, R.M.S.; SERRA, I.M.R.S.; MELO, T.A. Efeito de óleos essenciais como alternativa no controle de Colletotrichum gloeosporioides, em pimenta. Summa Phytopathol., Botucatu, v. 38, n. 1, p. 42-47, 2012.

VILLELA, J. G. A. Tratamento Químico De Sementes De Feijão (Phaseolus Vulgaris L.) para o Controle de Curtobacterium flaccumfaciens pv. flaccumfaciens. 132p. Dissertação (Mestrado do Programa de Pós Graduação em Fitopatologia) - Universidade de Brasília, Brasília, 2015.

XAVIER, M. V. A.et al. Viabilidade de sementes de feijão caupi após o tratamento com óleo essencial de citronela (Cymbopogon winterianus Jowitt). Revista Brasileira de Plantas Medicinais, Botucatu, v.14, $\mathrm{n}$. esp., p. 250-254, 2012. 